\title{
Risk Map for Facility Siting of an Ammonia-Urea Complex
}

\author{
Sultana Razia Syeda, Nuzhat Maisha and Anika Ferdous \\ Department of Chemical Engineering, Bangladesh University of Engineering and Technology, Dhaka 1000, \\ Bangladesh \\ Abstract: \\ In this study safer facility siting of an ammonia-urea complex is demonstrated by risk mapping. This risk map is \\ useful for identifying safer zones within the plant at the design stage as well as before setting temporary shelters, \\ i.e. shelters for contractors and maintenance workers etc. in an existing plant. To prepare the risk map a number of \\ critical process units of an ammonia- urea complex are selected as the sources of toxic release and blast \\ overpressure. Locations of control room and three operators' shelters are considered with respect to five critical \\ units. Consequences of toxic release and blast overpressure are modeled for various worst case scenarios \\ developed in the critical units. Both structural damage and human mortality/injury are converted into risk scores. \\ Risk mapping of the battery limit area are done and locations with minimum risk scores within plant area are \\ identified for the probable siting of the control room and operators' shelters. The findings are compared with the \\ layout of an existing ammonia-urea complex. It is also shown that a simple risk mapping of the plant area is \\ helpful in avoiding facility siting in high risk zone at the same time finding safer locations for different facilities.
}

Keyword: Facility siting; ammonia-urea plant; risk score

\section{Introduction}

Layout of equipment and facilities within a process plant is critical for both plant economy and plant safety. A good layout not only reduces plant capital cost but also improves operational safety with reduced environmental impact. On the other hand, improper layout such as control room in close proximity of process equipment, plant location in downwind direction of tank farm, fire station near the processing area, process area very close to residential area etc. increases the risk of fatality and property damage. Bedsides, poor layout design results in complicated and inadequate access to individual items of the plant hindering effective operation and maintenance as well as emergency response. In past, heuristics and graph methods were used for facility layout, which only considered best use of the available plant area[1-3]. The current methodologies also incorporate risk and economic factors in configuring layout[4-6]. Jung (2010) proposed grid based optimization of facility considering both risk and economic analysis. This approach has been used successfully to obtain globally optimum solution of layout arrangement problem[7].

Urea fertilizer represents $55 \%$ of total nitrogen output of the world and is one of the most widely used nitrogenous fertilizers. The current global urea capacity is around 208 million ton, which would increase to 252 million ton by 2019.New urea capacity is emerging in East Asia, Africa and North America. East Asia would contribute $36 \%$ of the net capacity increase, followed by Africa (22\% share) and North America (13\%). Close to sixty new units are to be installed worldwide during this time frame of which 25 would be located in China[8].Generally, urea fertilizer factory complex consists of ammonia synthesis and urea manufacturing plants. In order to be sustainable the new plants are adopting more integrated and compact unit operations, which necessitate detailed safety technology.
A number of accidents in ammonia and urea plants have been reported in last twenty years and some of the major accidents took place in last 10 years. These accidents took place in developing countries such as in India, Bangladesh, and China as well as in developed countries such as in UK and USA. For example, on March 21, 2005, in a fertilizer plant at Pingyin county, Shandong province, a urea synthesis reactor exploded. It killed four persons, seriously injured 32 people, and brought direct economic losses up to 4.3 million US dollar. Other accidents include fire and explosion due to mixture of hydrogen, nitrogen and ammonia in Terra Nitrogen Plant, UK, on June 1, 2006, caused by failure of pipeline; ammonia vessel blast in Vatva Ammonia Plant, India, on April 12, 2010, due to rise of temperature and pressure build up etc.[9-11]. Furthermore, two major accidents in Bangladesh took place in a single fertilizer factory, namely, Urea Fertilizer Factory Limited (UFFL) in 1974 and 1991. Both accidents affected control room occupants that led to increased number of fatalities along with property damage. The accident of 1991 occurred due to welding failure of $\mathrm{CO}_{2}$ stripper of urea plant that claimed eleven lives and injured several others. The location of the control room was particularly critical behind the high death toll[12].This was indeed a facility layout problem. Very recently, on August 26, 2016, yet another accident took place in Di-ammonium phosphate plant in Chittagong, Bangladesh, where ammonia release caused by failure of storage tank occurred.

In ammonia plant most of the accidents are related to ammonia release. The probability of explosion/fire related accidents, however, cannot be neglected as natural gas and hydrogen exist in high pressure units. In urea manufacturing plant the possibility of ammonia release as well as explosion due to formation of explosive gas mixtures of oxygen and hydrogen exist in units like urea reactor, $\mathrm{CO}_{2}$ scrubber etc. The accidents 


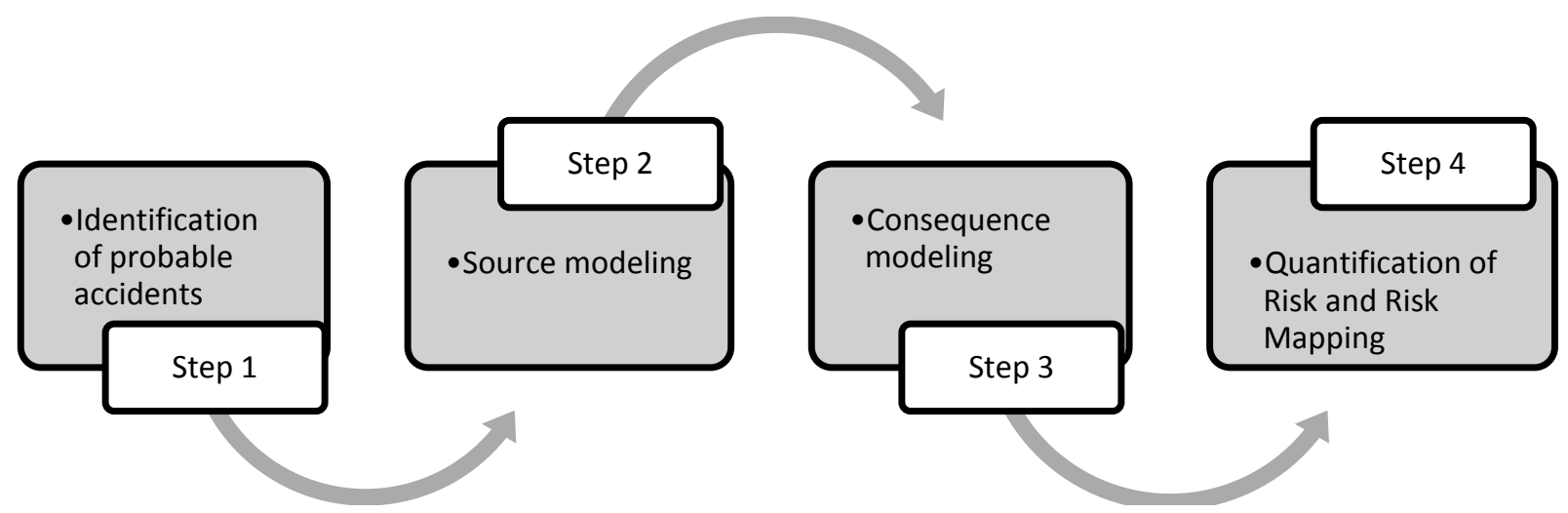

Figure 1: Steps used for risk quantification and risk mapping

are reported to be initiated mostly by failure of vessels and pipelines caused by corrosion, hydrogen embrittlement, or runaway reaction [13-17]. The other factors involved are failure of reformer tubes and valves etc.[18-20].

All failures have certain consequences and impacts on the adjacent area. In order to design a layout with minimum risk, the knowledge of potential impact of these failures on the adjacent facilities and their occupants is vital. The present work is aimed to provide an easy way to check risk associated with different locations within the battery limit of a plant. Grid based risk mapping of an existing ammonia-urea plant is done following the methodology developed by Jung (2010)[7]. Three main units of ammonia plant, namely, the primary reformer, secondary reformer and the ammonia converter and two units of urea plant, namely, the urea converter and high pressure carbon dioxide stripper have been considered for accidental release. Layout of an existing ammonia-urea plant is used to identify safe locations for control room and operators' shelters. Combined risk scores due to toxic release and vapor cloud explosion are determined.

It is to be noted that although fertilizer factories follow well established design methodology, poor facility siting in some plants as reported above intensified the consequences of a number of recent accidents. Besides, research integrating risk estimation in the configuration of plant layout in general has not been sufficiently reported in literature. The present study on ammoniaurea fertilizer complex will show how a very simple risk mapping can help a long way to determine safer and more economic location for facilities like control room and operating shelters. In this study ALOHA, a free and user friendly software, is used for estimating release consequences. Different data for urea fertilizer factory are incorporated in risk scores so that the method is ready to use in such factories.

\section{Methodology}

The steps followed for quantification of risk and risk mapping of the process plant are given below and represented in figure 1.
1. Identification of probable accidents

2. Source modeling

3. Consequence modeling

4. Quantification of Risk

5. Risk Mapping

At first the accident scenarios are set. In this study rupture of vessel is considered to be the leading causes of accidents. After selection of accident scenario, realistic accidents are considered with worst outcomes. The ruptures are considered to be of the size of holes of the largest pipe entering or exiting a unit. In order to incorporate the worst case scenario it is assumed that entire content within the unit is released upon the rupture within 10 minutes. The wind speed is considered to be $1.5 \mathrm{~m} / \mathrm{s}$ [21]. From the data available for annual average temperature, the ambient temperature is considered to be $32^{\circ} \mathrm{C}$. The relative humidity is considered to be $50 \%$. The substances released are considered to be at the exit temperature of each unit.

Dispersion of gas due to leakage or rupture in process equipments generally depends on wind speed, wind direction, atmospheric stability, ground conditions, and height of the release above the ground level, momentum and buoyancy of the initial material released. As the wind speed increases, the plume becomes longer and narrower. Consequently, the substance is carried downwind faster with more dilution by large quantity of air. One of the significant factors highlighted in this study is the effect of wind direction. In this study ALOHA is used for modeling the accidental release. The amount of release occurring is expressed either in the form of concentration or blast overpressure. The concentration/blast overpressure at a certain distance from the origin of source is determined for the toxic release/VCE. The concentrations and overpressures are converted into probit functions to determine probability of death. In case of toxic release, the probit function used for ammonia is,

$\operatorname{Pr}=-28.33+2.27\left(\ln \left(C^{1.36} * \mathrm{t}\right)\right)$

Here, $C$ is concentration in ppm and $t$ is time in minutes [22]. 


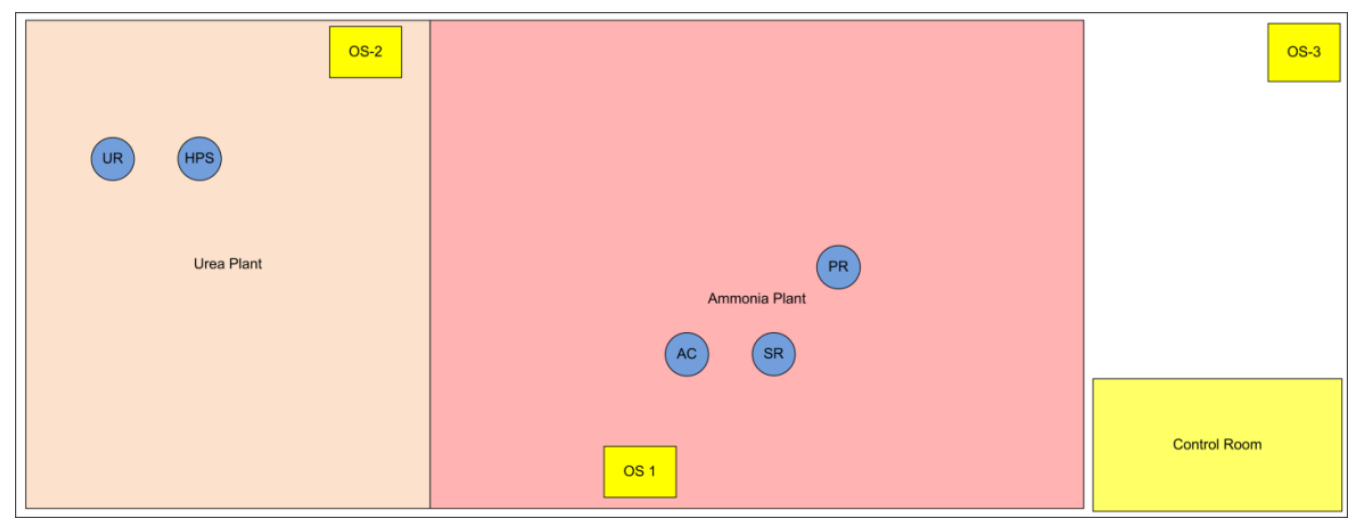

Figure 2: Simplified plot plan of the ammonia-urea complex showing major units and facilities

Unlike toxic release, persons who are exposed to overpressures have no time to react or take shelters. Thus, time does not enter into the hazard relationship. Work by the Health and Safety Executive, UK, has produced a probit relationship based on peak overpressure. This probit equation has the following form [23]:

$\operatorname{Pr}=1.47+1.37(\ln (\mathrm{P}))$

Where, $p=$ peak overpressure, psig .The probit values are then converted into risk scores. Risk score is the probability of toxic release or structural damage in the entire lifetime of the plant and is expressed as follows $[6,7]$ :

Risk Score $=$ Pr $\times$ frequency of occurrence $\times$ lifetime of plant $\times$ weighing factor

\section{Case Study: Evaluation of Facility Siting of an Existing Ammonia-Urea Plant}

The ammonia-urea complex under consideration resides in south-east part of Bangladesh having annual urea production capacity 0.56 million tons. The plant area under consideration is $100 \mathrm{~m}$ by $200 \mathrm{~m}$. At first the critical equipment were selected. These units were chosen based on their operating conditions and reported accident frequencies[24].The units are, namely, the ammonia converter, primary reformer, secondary reformer, urea synthesis reactor and high pressure stripper. The objective is to evaluate whether facilities, such as, control room or operators' shelters are safely sited with respect to these critical units. Figure 2 shows the current locations of the five units and three facilities on a simplified plot plan of the urea-ammonia plant battery limit. In the existing layout, the ammonia and urea plants share a common control room located at the south-east part of the complex outside of the processing area. There are three operators' shelters in the plant. The first and second shelters reside within the plant battery limit. The third one is situated at the north-east part of the complex outside of the plant battery limit. The location of the plant experiences annual wind mainly from north-west and south-east directions.
Table 1: Accident scenario of critical equipment

\begin{tabular}{|c|c|c|c|c|}
\hline Unit & Size & $\begin{array}{c}\text { Tempera } \\
\text { ture } \\
\left({ }^{\circ} \mathrm{C}\right) \\
\end{array}$ & $\begin{array}{l}\text { Pressure } \\
\left(\mathrm{kg} / \mathrm{cm}^{2}\right)\end{array}$ & $\begin{array}{c}\text { Accident } \\
\text { Considered }\end{array}$ \\
\hline \multirow{2}{*}{$\begin{array}{l}\text { Ammonia } \\
\text { Converter }\end{array}$} & Diameter: $3 \mathrm{~m}$ & \multirow[b]{2}{*}{439} & \multirow[b]{2}{*}{140} & \multirow{2}{*}{$\begin{array}{l}\text { Toxic release of } \\
\text { ammonia } \\
\text { Blast over pressure } \\
\text { due to VCE of } \\
\text { hydrogen }\end{array}$} \\
\hline & Length: $24 \mathrm{~m}$ & & & \\
\hline \multirow{2}{*}{$\begin{array}{l}\text { Primary } \\
\text { Reformer }\end{array}$} & Diameter: $3 \mathrm{~m}$ & \multirow{2}{*}{750} & \multirow{2}{*}{36} & \multirow{2}{*}{$\begin{array}{l}\text { Blast over pressure } \\
\text { due to VCE of } \\
\text { hydrogen }\end{array}$} \\
\hline & Length: $12 \mathrm{~m}$ & & & \\
\hline \multirow{2}{*}{$\begin{array}{l}\text { Secondary } \\
\text { Reformer }\end{array}$} & Diameter: $2 \mathrm{~m}$ & \multirow{2}{*}{950} & \multirow{2}{*}{38} & \multirow{2}{*}{$\begin{array}{l}\text { Blast over pressure } \\
\text { due to VCE of } \\
\text { hydrogen }\end{array}$} \\
\hline & Length: $8 \mathrm{~m}$ & & & \\
\hline \multirow{2}{*}{$\begin{array}{l}\text { Urea } \\
\text { Converter }\end{array}$} & Diameter: $3.8 \mathrm{~m}$ & \multirow{2}{*}{183} & \multirow{2}{*}{141.4} & \multirow{2}{*}{$\begin{array}{l}\text { Toxic release of } \\
\text { ammonia }\end{array}$} \\
\hline & Length: $30 \mathrm{~m}$ & & & \\
\hline \multirow{2}{*}{$\begin{array}{l}\text { High } \\
\text { Pressure } \\
\text { Stripper }\end{array}$} & Diameter: $2.2 \mathrm{~m}$ & \multirow{2}{*}{175} & \multirow{2}{*}{176} & \multirow{2}{*}{$\begin{array}{l}\text { Toxic release of } \\
\text { ammonia }\end{array}$} \\
\hline & Length: $19.3 \mathrm{~m}$ & & & \\
\hline
\end{tabular}

For the present study, the plant area is divided into 10 by 20 grids. Each grid is of a square of 10 meters on each side. It is assumed that each unit is contained in a single gird. For each unit, toxic releases of ammonia and/or blast overpressure for vapor cloud explosion (VCE) due to hydrogen are considered. The accident scenarios considered are:

- Rupture of ammonia converter

- Rupture of primary reformer

- Rupture of secondary reformer

- Rupture of urea synthesis reactor

- Rupture of high pressure stripper

Table 1 summarizes the size, operating conditions and accident scenarios of the critical equipment.

Risk score of each gird is calculated using equation (3). $P r$ in equation (3) is the probit function. Values of concentration of toxic release and blast overpressure obtained from ALOHA are used to get probit functions using equation (1) and (2). The lifetime of the plant is considered 20 years and the weighing factor is taken 100. Table 2 presents the frequencies of occurrence of different accidents considered in this study[23, 25]. Ammonia converter, primary reformer, secondary reformer and urea converter are considered as reactors, and the high pressure stripper is considered as a shell and tube heat exchanger. 


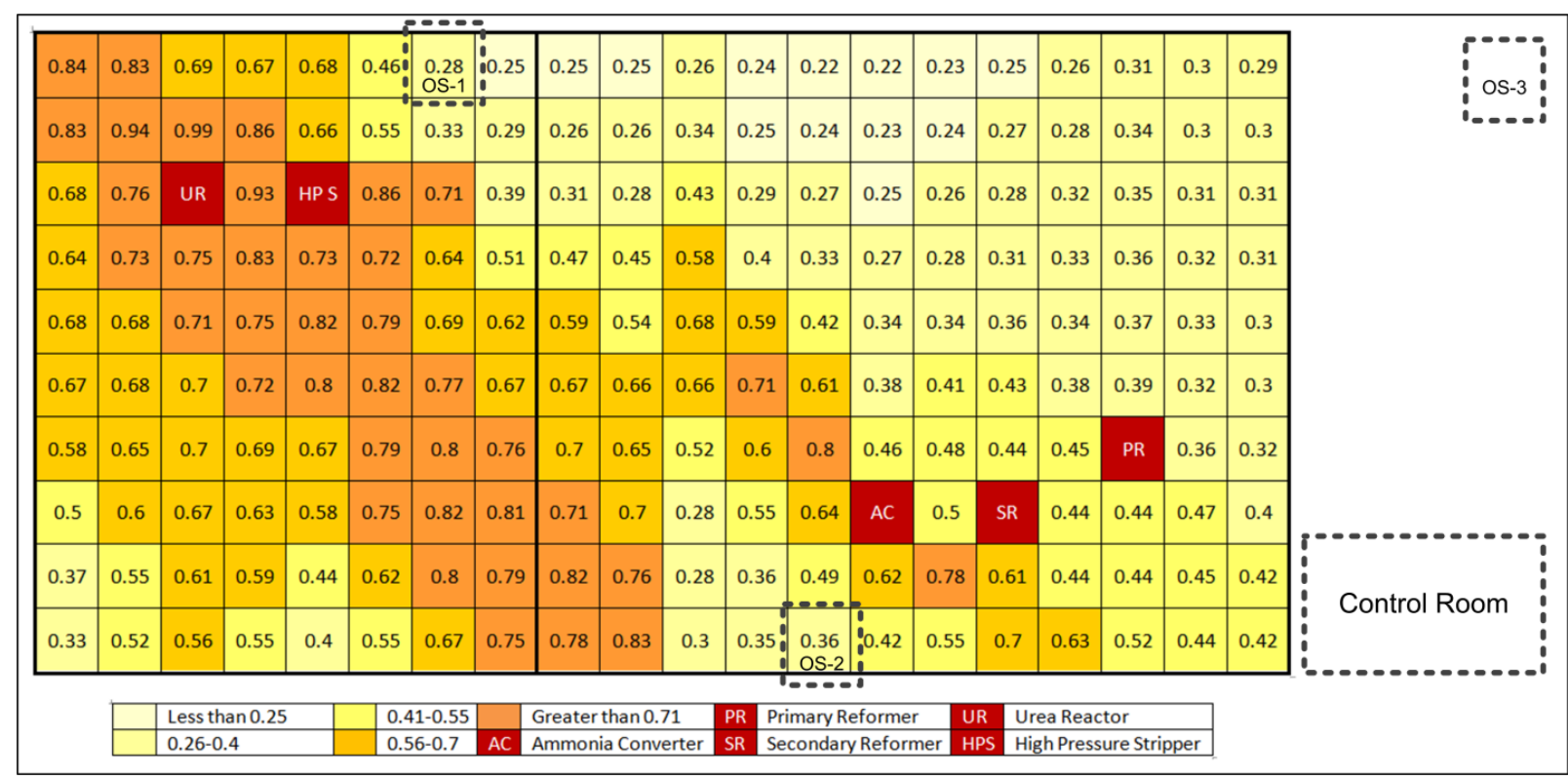

Figure 3: Risk map of ammonia-urea manufacturing complex

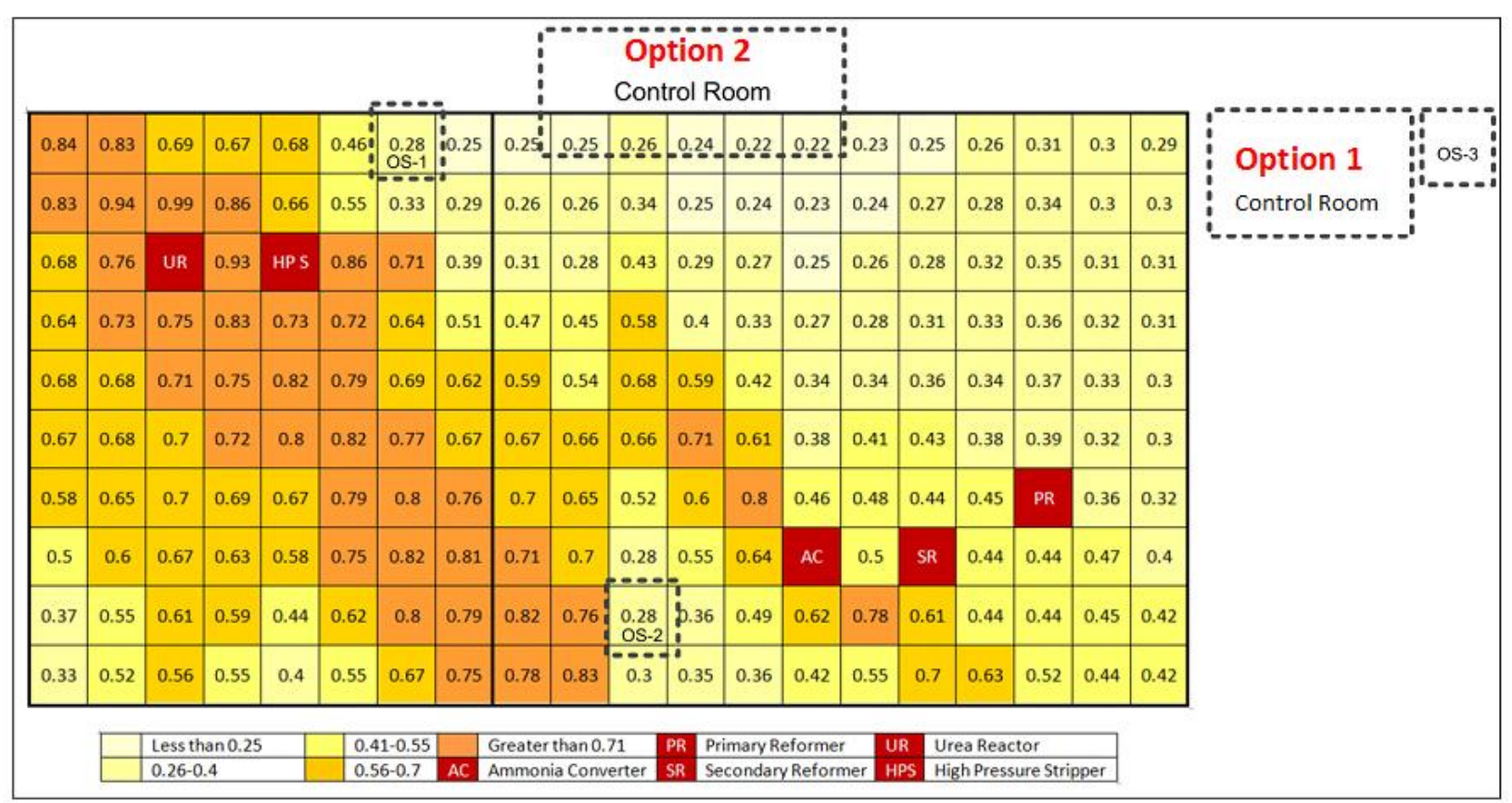

Figure 4: Suggested locations for control room and operators' shelters

Figure 3 shows the estimated risk scores for different grids i.e. the risk map of the plant area. The scores shown in the grids are combined risk scores obtained from toxic release and blast overpressure for five units. The values vary from 0.22 to 0.93 . The risk scores are dominated by the impact of toxic release. As expected the annual wind directions played the key role in determining the trend of risk scores in the risk map. The relatively high risk scores at the north-west and southeast directions of the process units reflect this effect.

In the existing layout, the control room is at the southeast corner of the complex outside the battery limit. It is next to ammonia plant and more than $120 \mathrm{~m}$ away from urea plant. When wind comes from the north-west direction, the control room is susceptible to higher risk of ammonia release compared to any other locations north to it. Figure 3 also shows that the location of operators' shelter 1, 2 and 3 are somewhat in lower risk zone. The most significant finding of this risk analysis is that the lowest risk scores are along the north boundary of the ammonia plant.

Figure 4 shows suggestions for safe locations for the facilities based on the estimated risk scores. While operator's shelter-1and operator's shelter-3 have safer 
locations in present layout, moving the operator's shelter-210-20m towards north-east would place it in a relatively low risk zone compared to the current location. On the other hand, the map suggests two safer options for locating the control room. Considering the high risk scores at the south-east part of the layout, a safer option for siting the control room would be at the top right i.e. north-east corner of the complex compared to the present location. However, the existence of relatively safe zone between the urea and ammonia plant at the north boundary is of great interest from both design and operational perspectives. Since the control room is shared by both urea and ammonia plants, locating the room between the two plants along the north boundary (i.e. the option 2) will reduce the cost of wiring and piping significantly. One can comprehend the importance of piping design from piping costs, which can run as high as $80 \%$ of the cost of purchased equipment and hence, constitute a substantial part of the capital cost [7]. Besides, option 2 will make operators' movement between control room and each plant site more convenient.

\section{Conclusion}

A simple risk map is built to determine safe locations for facilities of an ammonia-urea complex. In the risk map structural damage and human mortality/injury due to toxic release and blast overpressureare converted into risk scores, and locations with minimum risk scores within plant area are identified for the probable siting of control room and operators' shelters. The findings are compared with existing layout of an ammonia-urea complex. It is found that with help of the generated risk map facility siting in high risk zone can be avoided at the same time locations safer and more suitable from design and operational perspective can be determined.

\section{References}

1. Georgiadis, M.C., Macchietto, S., Layout of process plants: a novel approach. Computers and Chemical Engineering, 1997. 21: p. 6.

2. Jayakumar. S., R., G.V., Chemical plant layout via graph partitioning-I. Single level. Computers and Chemical Engineering, 1994. 18(5): p. 18.

3. Jayakumar, S., Reklaitis, G.V., Chemical plant layout via graph partitioning-II. Multiple levels. Computers and Chemical Engineering, 1996. 20(5): p. 16.

4. Guidelines for facility siting and layout. 2003, AICHE/CCPS: New York.

5. Jung, S., Ng, D., Laird, C. D., and Mannan, M.S., A new approach for facility siting using mapping risks on a plant grid area and optimization. Journal of Loss Prevention in the Process Industries, 2010. 23: p. 7.

6. Jung, S., Ng, D., Diaz-Ovalle, C., Vazquez-Roman, R., Mannan, M. S., New approach to optimizing the facility siting and layout for fire and explosion scenarios. Industrial \& Engineering Chemistry Research, 2011. 50: p. 10.
7. Jung, S., Facility siting and layout optimization based on process safety, , in Chemical Engineering. 2010, Texas A \& M University: Texas,USA.

8. World fertilizer trends and outlook to 2018. 2015, Food and Agriculture Organization of The United Nations: Rome.

9. Explosion at ammonia plant. 2006, Royal Society of Chemistry: UK.

10. Express, T.I., Blast at Vatva ammonia plant kills one. 2010.

11. Maruthappa, S. Case study on major chemical disasters. in Symposium on Prevention of Industrial/Chemical Disasters. 2009. Bengaluru, India. .

12. Quader, A. Carbon dioxide stripper failure of UFFL on June 20, 1991 in its ACES loop. in 4th Biennial Convention of BCIC Engineers' Association. 1993. Dhaka, Bangladesh.

13. Production of Urea and Urea Ammonium Nitrate: Best available techniques for pollution prevention and control in the European fertilizer industry. 2000.

14. Abduh, M., Integrity Engineering \& MARSH risk consulting

https://abduh137.wordpress.com/2008/04/28/the-50major-engineering-failures-1977-2007-part-2/. 2015.

15. Alhabdan, F.M., Elnashaie, S. S. E. H., , Simulation of an Ammonia Plant Accident Using Rigorous Heterogeneous Models: Effect of Shift Converters Disturbances on the Methanator. MAthematical and Computer Modelling, 1995. 21(4): p. 22.

16. Harjac, S.J., Atrens, A., Moss, C. J., Six Sigma Review of Root Causes of Corrosion Incidents in Hot Potassium Carbonate Acid Gas Removal Plant. Engineering Failure Analysis, 2008. 15: p. 17.

17. Wang, W., Li, A., Zhu, Y., Xiaojing, Y., Liu, Y., Chen, $\mathrm{Z}$., The explosion reason analysis of urea reactor of Pingyin,. Engineering Failure Analysis, 2009. 16(3).

18. Kumar, R.A., Sinha, S. K., Tiwari, Y. N., Swaminathan, J., Das, G., Chaudhuri, S., Singh, R., Analysis of failed reformer tubes. Engineering Failure Analysis, 2003. 10: p. 12.

19. Singh, J., Joshi, M. D., Desai, U. R., A natural gas feed preheater fire. Process Safety Progress, 2000. 19(1): p. 8.

20. Sparrow, R.E., Firebox explosion in a primary reformer furnace. Plant/Operations Progress, 1986. 5(2): p. 7.

21. Crowl, D.A., Louvar, J.F., Chemical process safety: Fundamentals with applications. . 3rd ed. 2011, New Jersey: Prentice Hall International Series in the Physical and Chemical Engineering Sciences.

22. Preliminary quantitative risk analysis (QRA) of the Texas clean energy project. 2010, Quest Consultants Inc.: NW,USA.

23. Failure rate and event data for use within risk assessments. 2012, HSE: UK.

24. Rahman, S.M.T., Salim, M.T., Sultana S. R., Facility layout optimization of an ammonia plant based on risk and economic analysis. Procedia Engineering, , 2014. 90: p. 6.

25. Collie urea project: preliminary risk assessment. 2009, Perdaman chemicals \& fertilizers Perth,AU. 